\title{
Review of Experimental GAPT and Infrared Atomic Charges in Molecules
}

\author{
Wagner E. Richter, Leonardo J. Duarte, Arnaldo F. Silva and Roy E. Bruns* \\ Instituto de Química, Universidade Estadual de Campinas (Unicamp), \\ CP 6154, 13083-970 Campinas-SP, Brazil
}

\begin{abstract}
This review contains experimental values of polar tensors and generalized atomic polar tensor (GAPT) charges determined since the publication of the polar tensor formulism for infrared intensity interpretation in 1961. GAPT charges, also called mean dipole moment derivatives, for 167 atoms of 67 molecules are discussed and compared with infrared charges also determined completely from experimental intensities. The importance of the charge transfer and polarization dynamic contributions to the GAPT charge are emphasized as they differentiate this charge from most theoretically calculated charges. The inclusion of these dynamic contributions is shown to be necessary to provide adequate numerical descriptions of core electron ionization energy processes. These contributions are expected to be important in studies of chemical reactivity.
\end{abstract} QTAIM

Keywords: atomic charges, infrared spectroscopy, ionization energies, atomic polar tensors,

\section{Introduction}

Atomic charge is the most frequently used molecular parameter containing electronic structure information for predicting chemical reactivities. In spite of this there does not exist a universally accepted procedure to calculate these charges even though a large number of methods have been proposed. ${ }^{1-11}$ Indeed, some types of atomic charge appear to be useful in various applications whereas others seem more appropriate in different problems. Since the definitions of atomic charge vary it is not always clear whether comparisons of different kinds of charge values are conceptually valid exercises. Furthermore, as most charges have been determined from molecular wave functions limited basis sets and inexact electronic correlation treatment levels hinder these efforts. However, it does appear as though different charge values owing to alternative definitions are more pronounced than those between quantum chemical and experimental results. ${ }^{12}$

Nowadays, experimental X-ray electronic densities can be obtained in routine experiments with quite high accuracy in solids. High-resolution experiments in the atomic $\left(\leq 1.0 \AA^{-1}\right)$ and sub-atomic (typically $\leq 0.7 \AA^{-1}$ ) regimes allow structural assignments with almost no error in the positions of the atoms. The charge density related to these experiments is well suited for analyses employing

*e-mail: bruns@iqm.unicamp.br quantum theory of atoms in molecules (QTAIM) ${ }^{13}$ or other topological partitions. Indeed, one of the most interesting and non-intuitive topological structures within the QTAIM theory is the non-nuclear attractor, and just recently an experimental characterization of such an entity was carried out using X-ray diffraction density with $1.1 \AA^{-1}$ resolution. ${ }^{14}$ The literature accounts for various studies ${ }^{15-17}$ dealing with experimental QTAIM charges from both ab initio procedures and X-ray densities and, in general, they are in good agreement with chemical insight.

Infrared intensities of fundamental bands of gas phase molecules contain a wealth of information about electronic structure and its changes on molecular vibration. The main objective of this review is to compile the values of the mean dipole moment derivatives, ${ }^{18}$ sometimes called generalized atomic polar tensor (GAPT) charges, ${ }^{19}$ determined solely from experimental data that are scattered throughout the chemical literature. A critical examination of these values is undertaken to ascertain whether the values comply with chemical experience. Now, dipole moment derivatives involve changes in the molecular dipole moment with respect to atomic vibrational displacements. As such, the GAPT charges have dynamic contributions not included in most atomic charge definitions. A short discussion about the agreement of the experimental values with those obtained from quantum chemical calculations is also included.

The second aim of this review is to make a conceptual and numerical comparison of the GAPT charge with infrared 
(IR) charges that have been proposed by Zerbi and coworkers. ${ }^{20,21}$ Within the point charge model approximation to molecular electronic structure descriptions these can also be determined from experimental infrared spectroscopic data for linear and planar molecules. In fact, these charges are equal to atomic polar tensor (APT) elements of perpendicular vibrations ${ }^{22}$ as the molecule must behave as a permanent dipole moment on rotation. ${ }^{23}$ As such, these derivatives are comparable to static atomic charges.

The next section deals with the calculational details used here to determine atomic polar tensors, GAPT and infrared charges. It is not necessary initial reading for those essentially interested in atomic charges that are discussed in the section immediately after the polar tensor methodology.

\section{Experimental Polar Tensor Calculations}

Infrared fundamental intensities of gas phase molecules determined from Beer's law plots of pressure broadened bands are proportional to the square root of the molecular dipole moment derivative with respect to the $j^{\text {th }}$ normal coordinate

$A_{j}=\frac{N_{A} \pi d_{j}}{3 c^{2}}\left(\frac{\partial \bar{p}}{\partial Q_{j}}\right)^{2} \quad j=1,2 \ldots 3 N-6$

where $\mathrm{N}_{\mathrm{A}}$ and $\mathrm{c}$ are Avogadro's number and the velocity of light, respectively, $d_{j}$ the degeneracy of the $j^{\text {th }}$ normal coordinate and $\mathrm{N}$ is the number of atoms in the molecule. ${ }^{24}$ Normal coordinates depend on force fields, masses of the atoms and molecular geometry. For this reason it is difficult to extract useful information from these derivatives about electronic structure changes on vibrations.

In contrast, atomic Cartesian coordinates are uniquely defined and particularly convenient for obtaining this information. Transforming from normal coordinates to atomic Cartesian coordinates results in the molecular polar tensor

$\mathbf{P}_{\mathbf{X}}=\left(\mathbf{P}_{\mathbf{x}}^{(1)} \mathbf{P}_{\mathbf{x}}^{(2)} \ldots \ldots \mathbf{P}_{\mathbf{x}}^{(\mathbf{N})}\right)$

that is a juxtaposition of atomic polar tensors, one for each atom in the molecule. ${ }^{25}$ The atomic polar tensor contains the derivatives of the $\mathrm{x}, \mathrm{y}$ and $\mathrm{z}$ dipole moment components with respect to the atomic Cartesian displacements of the $\alpha^{\text {th }}$ atom,

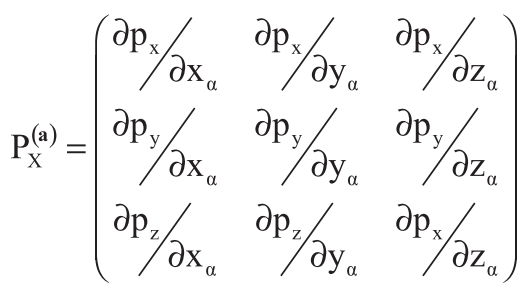

The details of the transformation from normal coordinates to atomic Cartesian coordinates addressed in the notations used in this review can be found in Person and Newton. ${ }^{25}$

Almost all the original experimental infrared intensity papers reported dipole moment derivatives and normal coordinates in terms of internal coordinates, $\mathbf{R}$, or symmetry coordinates, $\mathbf{S}$. Throughout the years, our research group transformed this data from normal coordinates into symmetry coordinates and/or internal coordinates and, finally, to atomic Cartesian coordinates. This necessitated the verifications of the transformations from normal coordinates to symmetry coordinates using the $\mathbf{L}$ normal coordinate matrix, internal coordinates to symmetry coordinates usually accomplished by the $\mathbf{U}$ matrix and atomic Cartesian coordinates to internal coordinates using the $\mathbf{B}$ or $\mathbf{D M}^{1 / 2}$ matrices,

$\mathbf{P}_{\mathbf{X}}=\mathbf{P}_{\mathbf{Q}} \mathbf{L}^{-1} \mathbf{U D M}^{1 / 2}+\mathbf{P}_{\boldsymbol{\rho}} \boldsymbol{\delta} \mathbf{M}^{1 / 2}$

where $\mathbf{P}_{\mathrm{Q}}$ is a $3 \times 3 \mathrm{~N}-6$ matrix of the $\mathrm{x}, \mathrm{y}$ and $\mathrm{z}$ dipole moment derivative components with respect to the $3 \mathrm{~N}-6$ normal coordinates and $\mathbf{P}_{\rho} \delta \mathrm{M}^{1 / 2}$ contains restraints owing to dipole moment changes to satisfy constant linear and angular momentum Eckart conditions.

The inverse transformation

$\mathbf{P}_{\mathbf{Q}}=\mathbf{P}_{\mathbf{X}} \mathbf{A} \mathbf{U}^{t} \mathbf{L}$

is normally employed to determine theoretical intensity values from quantum chemical estimates.

In summary, the experimental polar tensors reported here were calculated from: $(i)$ accurate absolute infrared intensities; (ii) theoretical and/or isotopically invariant criterion determinations of the signs of the $\partial \overrightarrow{\mathrm{p}} / \partial \mathrm{Q}_{\mathrm{j}} ;$ (iii) validated normal coordinates of those reported in the original papers containing the intensity values; and (iv) experimental geometries and permanent dipole moment values.

Precision of the infrared intensities and propagated derivatives in some cases were estimated by comparison of derivatives for H/D isotopically substituted molecules.

Polar tensor elements depend on molecular orientation relative to the space-fixed Cartesian coordinate system. However five invariant electronic properties ${ }^{26}$ can be calculated for the atomic polar tensors that are useful for the interpretation of infrared intensities. The parameter most commonly discussed is the trace of the atomic polar tensor called the mean dipole moment derivative ${ }^{18}$ or GAPT charge ${ }^{19}$ defined as

$\overline{\mathrm{p}}_{\alpha}=\frac{1}{3}\left(\mathrm{p}_{\mathrm{xx}}^{\alpha}+\mathrm{p}_{\mathrm{yy}}^{\alpha}+\mathrm{p}_{\mathrm{zz}}^{\alpha}\right)$ 
for the $\alpha^{\text {th }}$ atom. The tensor anisotropy given by

$$
\begin{aligned}
\beta_{\alpha}^{2}= & \left(\frac{1}{2}\right)\left[\left(p_{x x}-p_{y y}\right)^{2}+\left(p_{y y}-p_{z z}\right)^{2}+\left(p_{z z}-p_{x x}\right)^{2}+\right. \\
& \left.3\left(p_{x y}^{2}+p_{y z}^{2}+p_{x z}^{2}+p_{z x}^{2}+p_{y x}^{2}+p_{z y}^{2}\right)\right]
\end{aligned}
$$

is related to molecular symmetry. The square of the atomic effective charge

$\chi_{\alpha}^{2}=\left(\frac{1}{3}\right) \operatorname{Tr}\left(\mathbf{P}_{\mathrm{x}}^{(\alpha) \mathrm{t}} \mathbf{P}_{\mathrm{x}}^{(\alpha)}\right)$

is a sum of the squares of all the atomic polar tensor elements where Tr represents the trace. It is directly related to the sum of all the molecular fundamental band intensities. Two less frequently used invariants are the determinant of the atomic polar tensor, Det, and the sum of its cofactors given by

Cof $=p_{x x} p_{y y}+p_{y y} p_{z z}+p_{x x} p_{z z}+p_{x y} p_{y x}+p_{y z} p_{z y}+p_{x z} p_{z x}$

\section{Experimental GAPT Charges}

Table 1 contains the five atomic polar tensor invariant values for 167 atoms of 67 molecules. These were calculated from the atomic polar tensors using equations 6-9 and homemade software written in FORTRAN 90. The atomic polar tensor values are scattered in the literature ${ }^{27-68}$ and have been united in Table S1 (Supplementary Information). Frequently, these values are averages of tensors obtained from isotopomeric results or from work done by different research groups. Error values are included if they were given in the original literature. Sometimes they were estimated from the dispersions of Beer's law plots and others determined from differences of multiply reported tensor values.

Principal component analysis was carried out on these invariant values showing that the GAPT charge is highly correlated with three other parameters, the effective charge, the cubic root of the tensor determinant and the square root of the sum of the cofactors. The anisotropy values are not correlated and as such contain information not present in

\begin{tabular}{|c|c|c|c|c|c|c|c|}
\hline Molecule & Atom $^{\mathrm{a}}$ & $\overline{\mathrm{p}}_{\alpha}$ & $\beta_{\alpha}$ & $\left|\chi_{\alpha}\right|$ & $\mathrm{D}_{\alpha}^{1 / 3}$ & $|\mathrm{C}|_{\alpha}^{1 / 2}$ & IR charge / e \\
\hline \multirow[t]{3}{*}{$\mathrm{CH}_{3} \mathrm{~F}$} & $\mathrm{C}$ & 0.550 & 0.552 & 0.608 & 0.497 & 0.898 & - \\
\hline & $\mathrm{F}$ & -0.479 & 0.605 & 0.557 & -0.408 & 0.752 & - \\
\hline & $\mathrm{H}$ & -0.021 & 0.191 & 0.092 & -0.042 & 0.096 & - \\
\hline \multirow[t]{3}{*}{$\mathrm{CH}_{2} \mathrm{~F}_{2}$} & $\mathrm{C}$ & 1.015 & 0.644 & 1.060 & 0.972 & 1.719 & - \\
\hline & $\mathrm{F}$ & -0.488 & 0.640 & 0.574 & -0.415 & & - \\
\hline & $\mathrm{H}$ & -0.018 & 0.162 & 0.079 & -0.041 & 0.073 & - \\
\hline \multirow[t]{3}{*}{$\mathrm{CHF}_{3}$} & $\mathrm{C}$ & 1.518 & 0.635 & 1.548 & 1.485 & 2.604 & - \\
\hline & $\mathrm{H}$ & -0.003 & 0.104 & 0.049 & -0.042 & 0.060 & - \\
\hline & $\mathrm{F}$ & -0.505 & 0.670 & 0.595 & -0.430 & 0.793 & - \\
\hline \multirow[t]{2}{*}{$\mathrm{CF}_{4}$} & $\mathrm{C}$ & 2.051 & 0.000 & 2.051 & 2.051 & 3.552 & - \\
\hline & $\mathrm{F}$ & -0.512 & 0.410 & 0.547 & -0.472 & 0.855 & - \\
\hline \multirow[t]{3}{*}{$\mathrm{CH}_{3} \mathrm{Cl}$} & $\mathrm{C}$ & 0.272 & 0.491 & 0.357 & 0.191 & 0.376 & - \\
\hline & $\mathrm{Cl}$ & -0.268 & 0.275 & 0.298 & -0.241 & 0.436 & - \\
\hline & $\mathrm{H}$ & -0.001 & 0.154 & 0.073 & 0.010 & 0.087 & - \\
\hline \multirow[t]{3}{*}{$\mathrm{CH}_{2} \mathrm{Cl}_{2}$} & $\mathrm{C}$ & 0.527 & 0.875 & 0.669 & 0.377 & 0.760 & - \\
\hline & $\mathrm{Cl}$ & -0.248 & 0.412 & 0.315 & -0.193 & 0.367 & - \\
\hline & $\mathrm{H}$ & -0.015 & 0.124 & 0.060 & 0.053 & 0.065 & - \\
\hline \multirow[t]{3}{*}{$\mathrm{CHCl}_{3}$} & $\mathrm{C}$ & 0.823 & 0.915 & 0.929 & 0.647 & 1.324 & - \\
\hline & $\mathrm{H}$ & -0.026 & 0.086 & 0.048 & 0.045 & 0.020 & - \\
\hline & $\mathrm{Cl}$ & -0.265 & 0.603 & 0.389 & -0.163 & 0.344 & - \\
\hline \multirow[t]{2}{*}{$\mathrm{CCl}_{4}$} & $\mathrm{C}$ & 1.043 & 0.000 & 1.043 & 1.043 & 1.807 & - \\
\hline & $\mathrm{Cl}$ & -0.261 & 0.398 & 0.322 & -0.158 & 0.389 & - \\
\hline \multirow[t]{3}{*}{$\mathrm{CH}_{3} \mathrm{Br}$} & $\mathrm{C}$ & 0.210 & 0.463 & 0.303 & 0.118 & 0.248 & - \\
\hline & $\mathrm{Br}$ & -0.204 & 0.177 & 0.220 & -0.189 & 0.338 & - \\
\hline & $\mathrm{H}$ & -0.002 & 0.157 & 0.070 & -0.029 & 0.090 & - \\
\hline \multirow[t]{3}{*}{$\mathrm{CH}_{3} \mathrm{I}$} & $\mathrm{C}$ & 0.134 & 0.341 & 0.209 & 0.052 & 0.122 & - \\
\hline & I & -0.114 & 0.003 & 0.114 & -0.114 & 0.197 & - \\
\hline & $\mathrm{H}$ & -0.007 & 0.122 & 0.075 & -0.058 & 0.066 & - \\
\hline
\end{tabular}

Table 1. Atomic polar tensor invariant values of 167 atoms in 67 molecules determined from polar tensors in Table S2 spectroscopic data 
Table 1. Atomic polar tensor invariant values of 167 atoms in 67 molecules determined from polar tensors in Table S2 spectroscopic data (cont.)

\begin{tabular}{|c|c|c|c|c|c|c|c|}
\hline Molecule & Atom $^{\mathrm{a}}$ & $\overline{\mathrm{p}}_{\alpha}$ & $\beta_{\alpha}$ & $\left|\chi_{\alpha}\right|$ & $\mathrm{D}_{\alpha}^{1 / 3}$ & $|C|_{\alpha}^{1 / 2}$ & IR charge / e \\
\hline \multirow[t]{3}{*}{$\mathrm{CFCl}_{3}$} & $\mathrm{C}$ & 1.367 & 0.120 & 1.368 & 1.366 & 2.367 & - \\
\hline & $\mathrm{F}$ & -0.486 & 0.602 & 0.563 & -0.416 & 0.766 & - \\
\hline & $\mathrm{Cl}$ & -0.294 & 0.662 & 0.428 & -0.148 & 0.356 & - \\
\hline \multirow[t]{3}{*}{$\mathrm{CF}_{2} \mathrm{Cl}_{2}$} & $\mathrm{C}$ & 1.636 & 0.433 & 1.649 & 1.623 & 2.823 & - \\
\hline & $\mathrm{F}$ & -0.585 & 0.653 & 0.661 & -0.516 & 0.940 & - \\
\hline & $\mathrm{Cl}$ & -0.233 & 0.562 & 0.353 & 0.225 & 0.251 & - \\
\hline \multirow[t]{3}{*}{$\mathrm{CF}_{3} \mathrm{Cl}$} & $\mathrm{C}$ & 2.033 & 0.680 & 2.058 & 2.009 & 3.499 & - \\
\hline & $\mathrm{Cl}$ & -0.148 & 0.725 & 0.544 & -0.244 & 0.602 & - \\
\hline & $\mathrm{F}$ & -0.629 & 0.741 & 0.719 & -0.540 & 1.001 & - \\
\hline \multirow[t]{3}{*}{$\mathrm{F}_{2} \mathrm{CO}$} & $\mathrm{C}$ & 1.514 & 1.469 & 1.664 & 1.292 & 2.480 & 0.53 \\
\hline & $\mathrm{O}$ & -0.554 & 0.477 & 0.598 & -0.509 & 0.918 & -0.31 \\
\hline & $\mathrm{F}$ & -0.484 & 0.786 & 0.610 & -0.339 & 0.702 & -0.11 \\
\hline \multirow[t]{3}{*}{$\mathrm{Cl}_{2} \mathrm{CO}$} & $\mathrm{C}$ & 1.243 & 1.612 & 1.457 & 0.849 & 1.942 & 0.20 \\
\hline & $\mathrm{O}$ & -0.587 & 0.677 & 0.667 & -0.486 & 0.939 & -0.20 \\
\hline & $\mathrm{Cl}$ & -0.337 & 0.829 & 0.516 & 0.000 & 0.340 & 0.00 \\
\hline \multirow[t]{3}{*}{$\mathrm{F}_{2} \mathrm{CS}$} & $\mathrm{C}$ & 1.175 & 1.620 & 1.401 & 0.759 & 1.807 & 0.12 \\
\hline & $\mathrm{S}$ & -0.257 & 0.577 & 0.374 & -0.131 & 0.294 & -0.04 \\
\hline & $\mathrm{F}$ & -0.450 & 0.904 & 0.620 & -0.224 & 0.580 & -0.04 \\
\hline \multirow[t]{3}{*}{$\mathrm{Cl}_{2} \mathrm{CS}$} & $\mathrm{C}$ & 0.893 & 1.586 & 1.165 & -0.677 & 1.248 & -0.15 \\
\hline & $\mathrm{S}$ & -0.295 & 0.716 & 0.449 & 0.171 & 0.296 & 0.04 \\
\hline & $\mathrm{Cl}$ & -0.298 & 0.853 & 0.501 & 0.175 & 0.178 & 0.06 \\
\hline \multirow[t]{3}{*}{$\mathrm{Br}_{2} \mathrm{CO}$} & $\mathrm{C}$ & 1.027 & 1.399 & 1.220 & 0.604 & 1.584 & 0.10 \\
\hline & $\mathrm{O}$ & -0.700 & 0.829 & 0.802 & -0.537 & 1.114 & -0.17 \\
\hline & $\mathrm{Br}$ & -0.160 & 0.431 & 0.259 & 0.121 & 0.153 & 0.04 \\
\hline \multirow[t]{3}{*}{$\mathrm{H}_{2} \mathrm{CO}$} & $\mathrm{C}$ & 0.575 & 0.571 & 0.636 & 0.497 & 0.938 & 0.16 \\
\hline & $\mathrm{O}$ & -0.477 & 0.409 & 0.515 & -0.439 & 0.790 & -0.33 \\
\hline & $\mathrm{H}$ & -0.052 & 0.243 & 0.126 & 0.036 & 0.100 & 0.08 \\
\hline \multirow{3}{*}{ cis- $\mathrm{C}_{2} \mathrm{H}_{2} \mathrm{~F}_{2}$} & $\mathrm{C}$ & 0.313 & 0.964 & 0.552 & -0.149 & 0.105 & -0.063 \\
\hline & $\mathrm{H}$ & 0.059 & 0.182 & 0.104 & -0.053 & 0.042 & 0.159 \\
\hline & $\mathrm{F}$ & -0.372 & 0.853 & 0.548 & -0.206 & 0.435 & -0.096 \\
\hline \multirow[t]{3}{*}{ cis- $\mathrm{C}_{2} \mathrm{H}_{2} \mathrm{Cl}_{2}$} & $\mathrm{C}$ & 0.160 & 0.952 & 0.476 & 0.246 & 0.449 & -0.106 \\
\hline & $\mathrm{H}$ & 0.047 & 0.171 & 0.093 & -0.063 & 0.052 & 0.147 \\
\hline & $\mathrm{Cl}$ & -0.206 & 0.579 & 0.342 & -0.071 & 0.180 & -0.041 \\
\hline \multirow[t]{4}{*}{$1,1-\mathrm{C}_{2} \mathrm{H}_{2} \mathrm{~F}_{2}$} & $\mathrm{C}_{1}$ & -0.274 & 0.276 & 0.303 & -0.231 & 0.446 & -0.329 \\
\hline & $\mathrm{C}_{2}$ & 0.977 & 1.224 & 1.134 & 0.676 & 1.537 & 0.161 \\
\hline & $\mathrm{H}$ & 0.072 & 0.314 & 0.164 & -0.109 & 0.026 & 0.162 \\
\hline & $\mathrm{F}$ & -0.423 & 0.913 & 0.604 & -0.243 & 0.525 & -0.078 \\
\hline \multirow[t]{2}{*}{$\mathrm{CH}_{4}$} & $\mathrm{C}$ & 0.015 & 0.000 & 0.015 & 0.015 & 0.026 & - \\
\hline & $\mathrm{H}$ & -0.004 & 0.167 & 0.079 & -0.028 & 0.095 & - \\
\hline \multirow[t]{2}{*}{$\mathrm{C}_{2} \mathrm{H}_{4}$} & $\mathrm{C}$ & 0.011 & 0.385 & 0.189 & -0.168 & 0.222 & -0.246 \\
\hline & $\mathrm{H}$ & -0.006 & 0.197 & 0.093 & 0.082 & 0.112 & 0.122 \\
\hline \multirow[t]{2}{*}{$\mathrm{C}_{2} \mathrm{H}_{6}$} & $\mathrm{C}$ & 0.064 & 0.171 & 0.103 & -0.090 & 0.050 & - \\
\hline & $\mathrm{H}$ & -0.021 & 0.223 & 0.107 & -0.075 & 0.123 & - \\
\hline \multirow[t]{4}{*}{$\mathrm{C}_{3} \mathrm{H}_{4}$ (propyne) } & $\mathrm{H}_{7}$ & 0.198 & 0.026 & 0.199 & 0.198 & 0.343 & - \\
\hline & $\mathrm{C}_{6}$ & -0.313 & 0.186 & 0.325 & -0.302 & 0.531 & - \\
\hline & $\mathrm{H}_{1}$ & 0.048 & 0.138 & 0.139 & -0.056 & 0.076 & - \\
\hline & $\mathrm{C}_{4}$ & 0.097 & 0.071 & 0.103 & 0.090 & 0.164 & - \\
\hline \multirow[t]{3}{*}{$\mathrm{C}_{3} \mathrm{H}_{4}$ (allene) } & $\mathrm{C}_{1}$ & 0.032 & 0.822 & 0.389 & 0.324 & 0.471 & - \\
\hline & $\mathrm{C}_{3}$ & -0.132 & 0.449 & 0.250 & 0.234 & 0.121 & - \\
\hline & $\mathrm{H}$ & 0.058 & 0.161 & 0.096 & 0.043 & 0.061 & - \\
\hline \multirow[t]{2}{*}{$\mathrm{C}_{3} \mathrm{H}_{6}$ (cyclopropane) } & $\mathrm{C}$ & 0.017 & 0.269 & 0.128 & -0.121 & 0.152 & - \\
\hline & $\mathrm{H}$ & -0.009 & 0.170 & 0.081 & 0.377 & 0.091 & - \\
\hline
\end{tabular}


Table 1. Atomic polar tensor invariant values of 167 atoms in 67 molecules determined from polar tensors in Table S2 spectroscopic data (cont.)

\begin{tabular}{|c|c|c|c|c|c|c|c|}
\hline Molecule & Atom $^{\mathrm{a}}$ & $\overline{\mathrm{p}}_{\alpha}$ & $\beta_{\alpha}$ & $\left|\chi_{\alpha}\right|$ & $\mathrm{D}_{\alpha}^{1 / 3}$ & $|\mathrm{C}|_{\alpha}^{1 / 2}$ & IR charge / e \\
\hline \multirow[t]{2}{*}{$\mathrm{C}_{6} \mathrm{H}_{6}$} & $\mathrm{C}$ & -0.027 & 0.199 & 0.098 & 0.091 & 0.105 & -0.119 \\
\hline & $\mathrm{H}$ & 0.027 & 0.199 & 0.098 & -0.091 & 0.105 & 0.119 \\
\hline \multirow[t]{3}{*}{$\mathrm{C}_{4} \mathrm{H}_{6}$ (butyne) } & $\mathrm{C}_{4}$ & 0.117 & 0.090 & 0.124 & 0.107 & 0.196 & - \\
\hline & $\mathrm{H}$ & 0.002 & 0.186 & 0.088 & 0.067 & 0.098 & - \\
\hline & $\mathrm{C}_{9}$ & -0.124 & 0.149 & 0.143 & -0.091 & 0.197 & - \\
\hline \multirow[t]{2}{*}{$\mathrm{C}_{2} \mathrm{H}_{2}$} & $\mathrm{H}$ & 0.201 & 0.018 & 0.201 & 0.200 & 0.347 & 0.205 \\
\hline & $\mathrm{C}$ & -0.201 & 0.018 & 0.201 & -0.200 & 0.347 & -0.205 \\
\hline \multirow[t]{3}{*}{$\mathrm{HCN}$} & $\mathrm{H}$ & 0.231 & 0.019 & 0.231 & 0.230 & 0.399 & 0.237 \\
\hline & $\mathrm{C}$ & -0.041 & 0.376 & 0.182 & -0.127 & 0.204 & 0.084 \\
\hline & $\mathrm{N}$ & -0.189 & 0.395 & 0.266 & 0.197 & 0.236 & -0.321 \\
\hline \multirow[t]{2}{*}{$\mathrm{CO}_{2}$} & $\mathrm{O}$ & -0.536 & 0.901 & 0.684 & -0.399 & 0.770 & -0.236 \\
\hline & $\mathrm{C}$ & 1.073 & 1.802 & 1.368 & 0.797 & 1.539 & 0.472 \\
\hline \multirow[t]{2}{*}{$\mathrm{CS}_{2}$} & $\mathrm{~S}$ & -0.344 & 1.284 & 0.696 & -0.204 & 0.441 & 0.084 \\
\hline & $\mathrm{C}$ & 0.688 & 2.568 & 1.392 & 0.408 & 0.882 & -0.168 \\
\hline \multirow[t]{3}{*}{ OCS } & $\mathrm{O}$ & -0.581 & 1.433 & 0.891 & -0.254 & 0.572 & -0.103 \\
\hline & $\mathrm{S}$ & -0.268 & 0.811 & 0.467 & 0.015 & 0.057 & 0.002 \\
\hline & $\mathrm{C}$ & 0.849 & 2.244 & 1.356 & 0.288 & 0.696 & 0.101 \\
\hline \multirow[t]{3}{*}{$\mathrm{N}_{1} \mathrm{NO}$} & $\mathrm{N}_{1}$ & -0.281 & 0.518 & 0.372 & -0.194 & 0.383 & -0.108 \\
\hline & $\mathrm{O}$ & -0.505 & 1.098 & 0.723 & -0.288 & 0.603 & -0.139 \\
\hline & $\mathrm{N}$ & 0.786 & 1.616 & 1.094 & 0.484 & 0.991 & 0.247 \\
\hline \multirow[t]{3}{*}{$\mathrm{ClCN}$} & $\mathrm{Cl}$ & -0.037 & 0.574 & 0.273 & -0.215 & 0.325 & 0.154 \\
\hline & $\mathrm{N}$ & -0.202 & 0.157 & 0.215 & -0.184 & 0.337 & -0.254 \\
\hline & $\mathrm{C}$ & 0.243 & 0.424 & 0.308 & 0.165 & 0.324 & 0.093 \\
\hline \multirow[t]{3}{*}{$\mathrm{BrCN}$} & $\mathrm{Br}$ & 0.070 & 0.369 & 0.188 & -0.187 & 0.175 & 0.193 \\
\hline & $\mathrm{N}$ & -0.192 & 0.102 & 0.198 & -0.185 & 0.327 & -0.226 \\
\hline & $\mathrm{C}$ & 0.122 & 0.267 & 0.175 & 0.069 & 0.145 & 0.033 \\
\hline \multirow[t]{2}{*}{$\mathrm{SiH}_{4}$} & $\mathrm{Si}$ & 0.918 & 0.000 & 0.918 & 0.918 & 1.590 & - \\
\hline & $\mathrm{H}$ & -0.229 & 0.119 & 0.235 & -0.222 & 0.390 & - \\
\hline \multirow[t]{2}{*}{$\mathrm{SiH}_{4}$} & $\mathrm{Si}$ & 0.904 & 0.000 & 0.904 & 0.904 & 1.566 & - \\
\hline & $\mathrm{H}$ & -0.226 & 0.026 & 0.226 & -0.226 & 0.392 & - \\
\hline \multirow[t]{2}{*}{$\mathrm{GeH}_{4}$} & $\mathrm{Ge}$ & 0.862 & 0.000 & 0.862 & 0.862 & 1.493 & - \\
\hline & $\mathrm{H}$ & -0.216 & 0.068 & 0.218 & -0.214 & 0.372 & - \\
\hline \multirow[t]{2}{*}{$\mathrm{SnH}_{4}$} & $\mathrm{Sn}$ & 1.016 & 0.000 & 1.016 & 1.016 & 1.760 & - \\
\hline & $\mathrm{H}$ & -0.254 & 0.081 & 0.257 & -0.251 & 0.437 & - \\
\hline \multirow[t]{2}{*}{$\mathrm{SiF}_{4}$} & $\mathrm{Si}$ & 2.215 & 0.000 & 2.215 & 2.215 & 3.836 & - \\
\hline & $\mathrm{H}$ & -0.554 & 0.121 & 0.557 & -0.551 & 0.957 & - \\
\hline \multirow[t]{4}{*}{$\mathrm{C}_{2} \mathrm{H}_{3} \mathrm{~N}$} & $\mathrm{C}_{1}$ & 0.110 & 0.102 & 0.120 & 0.096 & 0.181 & - \\
\hline & $\mathrm{H}_{1}$ & 0.034 & 0.127 & 0.069 & -0.028 & 0.031 & - \\
\hline & $\mathrm{C}_{2}$ & 0.067 & 0.017 & 0.067 & 0.066 & 0.115 & - \\
\hline & $\mathrm{N}$ & -0.278 & 0.160 & 0.288 & -0.266 & 0.472 & - \\
\hline \multirow[t]{2}{*}{$\mathrm{H}_{2} \mathrm{O}$} & $\mathrm{O}$ & -0.472 & 0.312 & 0.494 & -0.448 & 0.797 & -0.658 \\
\hline & $\mathrm{H}$ & 0.236 & 0.198 & 0.254 & 0.234 & 0.404 & 0.329 \\
\hline \multirow[t]{2}{*}{$\mathrm{C}_{6} \mathrm{~F}_{6}$} & $\mathrm{C}$ & 0.428 & 0.957 & 0.621 & 0.215 & 0.494 & 0.057 \\
\hline & $\mathrm{F}$ & -0.428 & 1.044 & 0.653 & -0.188 & 0.432 & -0.057 \\
\hline \multirow[t]{2}{*}{$\mathrm{NH}_{3}$} & $\mathrm{~N}$ & -0.101 & 0.634 & 0.316 & -0.185 & 0.321 & - \\
\hline & $\mathrm{H}$ & 0.034 & 0.356 & 0.171 & 0.039 & 0.064 & - \\
\hline $\mathrm{PH}_{3}$ & $\mathrm{P}$ & 0.357 & 0.116 & 0.361 & 0.353 & 0.614 & - \\
\hline & $\mathrm{H}$ & -0.119 & 0.120 & 0.132 & -0.107 & 0.194 & - \\
\hline $\mathrm{NF}_{3}$ & $\mathrm{~N}$ & 1.154 & 0.838 & 1.219 & 1.069 & 1.939 & - \\
\hline & F & -0.385 & 0.695 & 0.505 & -0.312 & 0.596 & - \\
\hline $\mathrm{PF}_{3}$ & $\mathrm{P}$ & 1.740 & 0.251 & 1.744 & 1.736 & 3.011 & - \\
\hline & $\mathrm{F}$ & -0.580 & 1.052 & 0.763 & -0.430 & 0.834 & - \\
\hline
\end{tabular}


Table 1. Atomic polar tensor invariant values of 167 atoms in 67 molecules determined from polar tensors in Table S2 spectroscopic data (cont.)

\begin{tabular}{|c|c|c|c|c|c|c|c|}
\hline Molecule & Atom $^{\mathrm{a}}$ & $\overline{\mathrm{p}}_{\alpha}$ & $\beta_{\alpha}$ & $\left|\chi_{\alpha}\right|$ & $\mathrm{D}_{\alpha}^{1 / 3}$ & $|\mathrm{C}|_{\alpha}^{1 / 2}$ & IR charge / e \\
\hline \multirow[t]{2}{*}{$\mathrm{BF}_{3}$} & B & 1.517 & 1.030 & 1.592 & 1.421 & 2.559 & 0.83 \\
\hline & $\mathrm{F}$ & -0.507 & 0.485 & 0.556 & -0.459 & 0.832 & -0.28 \\
\hline \multirow[t]{2}{*}{$\mathrm{BCl}_{3}$} & B & 0.747 & 0.940 & 0.868 & 0.513 & 1.174 & 0.12 \\
\hline & $\mathrm{Cl}$ & -0.247 & 0.465 & 0.330 & -0.149 & 0.332 & -0.04 \\
\hline \multirow[t]{3}{*}{$\mathrm{C}_{2} \mathrm{H}_{4} \mathrm{O}$} & $\mathrm{O}$ & -0.483 & 0.157 & 0.286 & 0.280 & 0.481 & - \\
\hline & $\mathrm{H}$ & -0.018 & 0.184 & 0.089 & 0.014 & 0.079 & - \\
\hline & $\mathrm{C}$ & 0.277 & 0.098 & 0.385 & 0.379 & 0.660 & - \\
\hline \multirow[t]{2}{*}{$\mathrm{C}_{2} \mathrm{~N}_{2}$} & $\mathrm{~N}$ & -0.122 & 0.368 & 0.212 & 0.197 & 0.017 & -0.245 \\
\hline & $\mathrm{C}$ & 0.122 & 0.368 & 0.212 & -0.197 & 0.017 & 0.245 \\
\hline \multirow[t]{2}{*}{$\mathrm{SO}_{2}$} & $\mathrm{O}$ & -0.504 & 0.700 & 0.602 & -0.435 & 0.825 & -0.235 \\
\hline & S & 1.016 & 1.125 & 1.140 & 0.887 & 1.641 & 0.471 \\
\hline \multirow[t]{2}{*}{$\mathrm{HF}$} & $\mathrm{H}$ & 0.382 & 0.098 & 0.385 & 0.379 & 0.660 & 0.415 \\
\hline & $\mathrm{F}$ & -0.382 & 0.098 & 0.385 & -0.379 & 0.660 & -0.415 \\
\hline \multirow[t]{2}{*}{$\mathrm{HCl}$} & $\mathrm{H}$ & 0.184 & 0.014 & 0.184 & 0.184 & 0.318 & 0.179 \\
\hline & $\mathrm{Cl}$ & -0.184 & 0.014 & 0.184 & -0.184 & 0.318 & -0.179 \\
\hline \multirow[t]{2}{*}{$\mathrm{HBr}$} & $\mathrm{H}$ & 0.114 & 0.021 & 0.114 & 0.114 & 0.197 & 0.121 \\
\hline & $\mathrm{Br}$ & -0.114 & 0.021 & 0.114 & -0.114 & 0.197 & -0.121 \\
\hline \multirow[t]{2}{*}{$\mathrm{HI}$} & $\mathrm{H}$ & 0.040 & 0.044 & 0.045 & 0.032 & 0.065 & 0.055 \\
\hline & I & -0.040 & 0.044 & 0.045 & -0.032 & 0.065 & -0.055 \\
\hline \multirow[t]{2}{*}{$\mathrm{LiH}$} & $\mathrm{H}$ & -0.654 & 0.271 & 0.666 & -0.640 & 1.121 & -0.747 \\
\hline & $\mathrm{Li}$ & 0.654 & 0.271 & 0.666 & 0.640 & 1.121 & 0.747 \\
\hline \multirow[t]{2}{*}{$\mathrm{CO}$} & $\mathrm{O}$ & -0.228 & 0.751 & 0.421 & -0.071 & 0.178 & 0.022 \\
\hline & $\mathrm{C}$ & 0.228 & 0.751 & 0.421 & 0.071 & 0.178 & -0.022 \\
\hline \multirow[t]{2}{*}{$\mathrm{LiF}$} & $\mathrm{F}$ & -0.861 & 0.071 & 0.861 & -0.860 & 1.490 & -0.837 \\
\hline & $\mathrm{Li}$ & 0.861 & 0.071 & 0.861 & 0.860 & 1.490 & 0.837 \\
\hline \multirow[t]{2}{*}{$\mathrm{LiCl}$} & $\mathrm{Cl}$ & -0.760 & 0.090 & 0.761 & -0.759 & 1.315 & -0.730 \\
\hline & $\mathrm{Li}$ & 0.760 & 0.090 & 0.761 & 0.759 & 1.315 & 0.730 \\
\hline \multirow[t]{2}{*}{$\mathrm{NaF}$} & $\mathrm{F}$ & -0.889 & 0.032 & 0.889 & -0.889 & 1.539 & -0.878 \\
\hline & $\mathrm{Na}$ & 0.889 & 0.032 & 0.889 & 0.889 & 1.539 & 0.878 \\
\hline \multirow[t]{2}{*}{$\mathrm{NaCl}$} & $\mathrm{Cl}$ & -0.809 & 0.053 & 0.809 & -0.808 & 1.400 & -0.791 \\
\hline & $\mathrm{Na}$ & 0.809 & 0.053 & 0.809 & 0.808 & 1.400 & 0.791 \\
\hline \multirow[t]{2}{*}{$\mathrm{KCl}$} & $\mathrm{Cl}$ & -0.830 & 0.092 & 0.830 & -0.829 & 1.436 & -0.799 \\
\hline & $\mathrm{K}$ & 0.830 & 0.092 & 0.830 & 0.829 & 1.436 & 0.799 \\
\hline \multirow[t]{2}{*}{ NO } & $\mathrm{O}$ & -0.151 & 0.541 & 0.297 & -0.076 & 0.170 & 0.029 \\
\hline & $\mathrm{N}$ & 0.151 & 0.541 & 0.297 & 0.076 & 0.170 & -0.029 \\
\hline
\end{tabular}

${ }^{a}$ The subindices in the atom column identify nonequivalent multiple atoms in the molecules. $\overline{\mathrm{p}}_{\alpha}$ : mean dipole moment derivative; $\beta_{\alpha}$ : square root of the anisotropy; $\left|\chi_{\alpha}\right|$ : absolute value of the effective charge; $D_{\alpha}^{1 / 3}$ : cubic root of the determinant; and $|C|_{\alpha}^{1 / 2}$ : square root of the absolute value of the sum of cofactors.

the GAPT charges. For this reason a bivariate analysis of the GAPT charge and the square root of the anisotropy values is the most fruitful option for recognizing meaningful data trends in the values of these invariants.

Figure 1 contains a graph of these invariants for central carbon atoms. Several trends are evident on its examination. The carbon atom GAPT charge normally increases with increasing electronegativity of its substituent atoms. For the halomethanes this is well-documented by an electronegativity model for their fundamental infrared intensity sums. ${ }^{69,70}$ This empirical model was recently confirmed by theoretical calculations of atomic contributions to individual infrared vibrations. ${ }^{71}$
The $\mathrm{X}_{2} \mathrm{CY}$ molecules also show this behavior as well as do $\mathrm{CO}_{2}$, OCS and $\mathrm{CS}_{2}$. As can be seen in Figure 1, GAPT charges of the hydrocarbons occur on the left of the graph close to the null charge value. The $\mathrm{CH}_{4}$ molecule has a carbon charge of +0.015 e. As expected the sp carbon in acetylene has a significant negative value, $-0.201 \mathrm{e}$, as its hydrogen atoms are widely recognized to be much more acidic than those bonded to $\mathrm{sp}^{2}$ and $\mathrm{sp}^{3}$ carbons.

Examination of the carbon GAPT charges in Figure 1 shows that the carbon charge becomes progressively more positive on substituting fluorine for hydrogen by an almost constant amount, about 0.5 e per substitution. The carbon charges in the fluoromethanes are $-0.015,0.550$, 


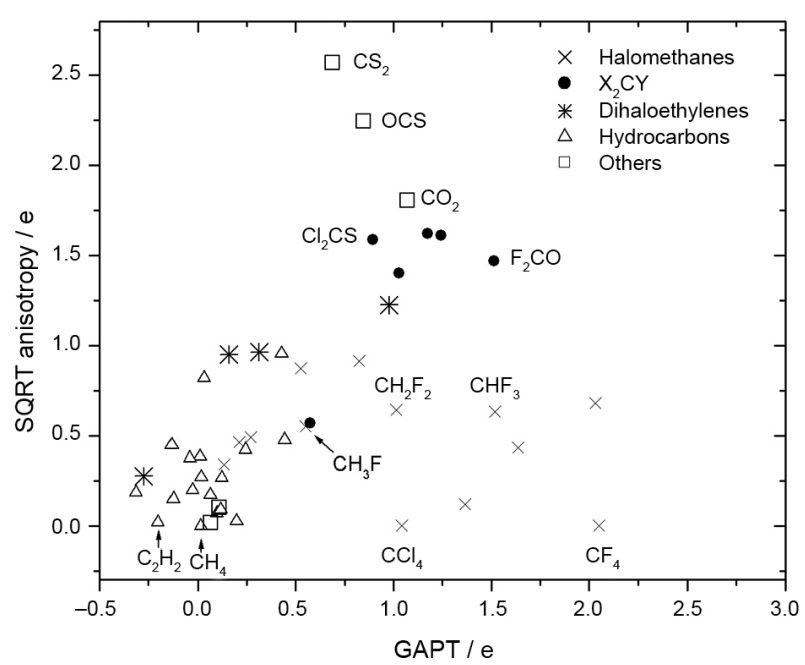

Figure 1. GAPT charges plotted against the square root (SQRT) of the anisotropy polar tensor invariants for the carbon atoms of the halomethanes, dihaloethylenes, $\mathrm{X}_{2} \mathrm{CY}$ and hydrocarbon molecules.

1.015, 1.518 and 2.015 e for $\mathrm{CH}_{4}, \mathrm{CH}_{3} \mathrm{~F}, \mathrm{CH}_{2} \mathrm{~F}_{2}, \mathrm{CHF}_{3}$ and $\mathrm{CF}_{4}$, respectively. This suggests that the halomethane molecules obey a characteristic substituent shift model (CSSM) that our group has already reported..$^{72}$ Substituting $\mathrm{F}$ for $\mathrm{H}$ in $\mathrm{CH}_{4}$ results in charge value change of $0.535 \mathrm{e}$. The difference in this charge between $\mathrm{CH}_{4}$ and $\mathrm{CH}_{3} \mathrm{Cl}$ is $0.257 \mathrm{e}$, characteristic of the $\mathrm{Cl}$ for $\mathrm{H}$ substitution. These calibration values lead to the characteristic substituent shift results for the other fluorochloromethanes in Table 2 compared with the values obtained directly from the polar tensors. Included in the table are estimates for $\mathrm{Cl}_{2} \mathrm{CS}$ from the $\mathrm{F}_{2} \mathrm{CO}, \mathrm{Cl}_{2} \mathrm{CO}$ and $\mathrm{F}_{2} \mathrm{CS}$ tensor values reported many years ago ${ }^{73}$ and for OCS obtained from the $\mathrm{CO}_{2}$ and $\mathrm{CS}_{2}$ values. All these values are plotted in Figure 2 showing good agreement between model and experimental values with a slope of 0.975 .

Table 2. GAPT charge values determined from experimental infrared spectroscopic data and by the characteristic substituent shift model

\begin{tabular}{lcc}
\hline Molecule & APT (experimental) / e & CSSM (transferred) / e \\
\hline $\mathrm{CH}_{2} \mathrm{~F}_{2}$ & 1.015 & 1.085 \\
$\mathrm{CHF}_{3}$ & 1.518 & 1.620 \\
$\mathrm{CF}_{4}$ & 2.015 & 2.155 \\
$\mathrm{CH}_{2} \mathrm{Cl}_{2}$ & 0.527 & 0.559 \\
$\mathrm{CHCl}_{3}$ & 0.823 & 0.831 \\
$\mathrm{CCl}_{4}$ & 1.043 & 1.103 \\
$\mathrm{CFCl}_{3}$ & 1.367 & 1.366 \\
$\mathrm{CF}_{2} \mathrm{Cl}_{2}$ & 1.636 & 1.629 \\
$\mathrm{CF}_{3} \mathrm{Cl}$ & 2.033 & 1.892 \\
$\mathrm{OCS}$ & 0.849 & 0.881 \\
$\mathrm{Cl}_{2} \mathrm{CS}$ & 0.893 & 0.904 \\
\hline $\mathrm{APT}$ & & $\mathrm{CSSM}$
\end{tabular}

APT: atomic polar tensor; CSSM: characteristic substituent shift model.

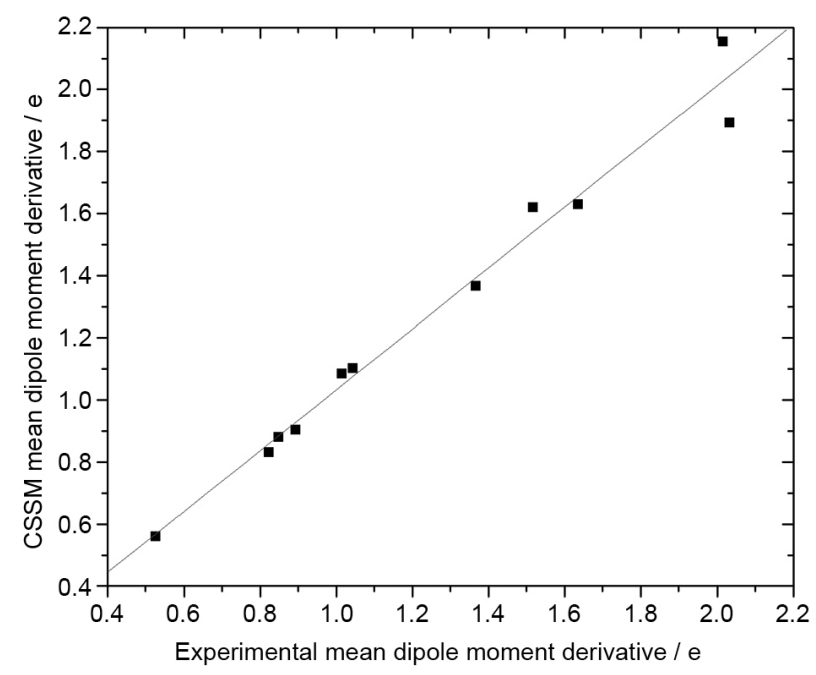

Figure 2. GAPT charge calculated directly from the experimental polar tensor $v s$. these charges estimated by the characteristic shift substituent model (CSSM).

The carbon anisotropy values appear to be higher for unsaturated than saturated molecules. The highest values occur for $\mathrm{CO}_{2}, \mathrm{OCS}$ and $\mathrm{CS}_{2}$ that range from 1.802 for $\mathrm{CO}_{2}$ to 2.568 e for $\mathrm{CS}_{2}$. The anisotropy value for carbon in OCS, $2.244 \mathrm{e}$, is close to the average of these two, $2.185 \mathrm{e}$. The $\mathrm{X}_{2} \mathrm{CY}$ molecules have carbon anisotropy values between 1.469 and 1.586 e. Difluoro- and dichloroethylene carbon atoms have somewhat lower values between 0.952 and $1.224 \mathrm{e}$. On the other hand, the anisotropy value for carbon in benzene is only $0.199 \mathrm{e}$ although it is much higher for $\mathrm{C}_{6} \mathrm{~F}_{6}, 0.957 \mathrm{e}$. The benzene value is intermediate between those for $\mathrm{C}_{2} \mathrm{H}_{4}, 0.385 \mathrm{e}$, and $\mathrm{C}_{2} \mathrm{H}_{6}, 0.171 \mathrm{e}$. The methane value is zero owing to $T_{d}$ symmetry. All the saturated molecules have values lower than 1.0 e with highest values for $\mathrm{CH}_{2} \mathrm{Cl}_{2}$ and $\mathrm{CHCl}_{3}$. Evidently, a combination of molecular asymmetry and heavier substituent atoms favors higher anisotropy values for these molecules.

Figure 3 shows a plot of the GAPT charge and the square root of the anisotropy values for all the terminal atoms except for those of the diatomic molecules in Table 1. The major trend shows more negative charge values as the atomic electronegativity increases. The fluorine atom charges in saturated molecules are relatively constant with an average mean dipole moment derivative of $-0.497 \mathrm{e}$ and a standard deviation of only $0.045 \mathrm{e}$. The charges on oxygen atoms participating in single and double bonds are $-0.540 \pm 0.070 \mathrm{e}$ and the chlorine ones $-0.285 \pm 0.059$ e. The oxygen GAPT charge is much less negative in $\mathrm{CO},-0.228 \mathrm{e}$. The bromine atomic charge in $\mathrm{CH}_{3} \mathrm{Br}$ is $-0.204 \mathrm{e}$ and in $\mathrm{Br}_{2} \mathrm{CO},-0.160 \mathrm{e}$. Interestingly, the fluorine and chlorine charges in the dihaloethylenes are less negatively charged than those in the saturated and $\mathrm{X}_{2} \mathrm{CY}$ molecules with values of -0.372 and -0.423 e for fluorine and -0.206 e for chlorine. 


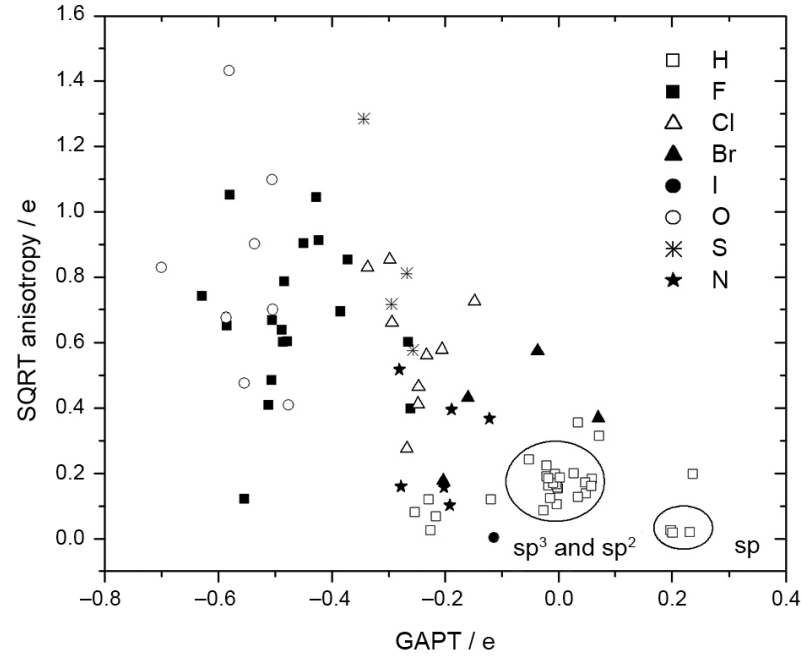

Figure 3. GAPT charges plotted against the square root of the anisotropy polar tensor invariants for the terminal atoms of the halomethanes, dihaloethylenes, $\mathrm{X}_{2} \mathrm{CY}$ and hydrocarbon molecules.

The hydrogen atomic charges cluster into three groups. The largest group close to the null charge contains hydrogens bonded to $\mathrm{sp}^{3}$ and $\mathrm{sp}^{2}$ carbon atoms. The group of three hydrogens with clearly positive charges around +0.200 e are those bonded to sp carbons in $\mathrm{C}_{2} \mathrm{H}_{2}$, propyne and $\mathrm{HCN}$. The three values between -0.2 and $-0.3 \mathrm{e}$ correspond to the hydrogens of the $\mathrm{MH}_{4}$ molecules $(\mathrm{M}=\mathrm{Si}$, $\mathrm{Ge}$ and $\mathrm{Sn}$ ). The charges on the central atoms of the $\mathrm{CH}_{4}$, $\mathrm{SiH}_{4}, \mathrm{GeH}_{4}$ and $\mathrm{SnH}_{4}$ molecules are $-0.004,+0.911,+0.862$ and $+1.016 \mathrm{e}$, reflecting the non-monotonic trend in their electronegativity values.

The GAPT charges of the $\mathrm{XY}_{3}$ molecules also follow electronegativity considerations. The hydrogen atom GAPT charge in ammonia is positive reflecting the high electronegativity of the nitrogen atom relative to phosphorus as the hydrogen atoms in phosphine have relatively large negative charges. This trend also occurs for the fluorine substituents in $\mathrm{NF}_{3}$ and $\mathrm{PF}_{3}$. The fluorine charge in $\mathrm{NF}_{3}$, $-0.385 \mathrm{e}$, is not as negative as those in $\mathrm{PF}_{3},-0.580 \mathrm{e}$.

The GAPT charges for the diatomic molecules listed near the end of Table 1 contain five clearly ionic molecules, $\mathrm{LiF}, \mathrm{LiCl}, \mathrm{NaF}, \mathrm{NaCl}$ and $\mathrm{KCl}$. Their metallic ions have positive GAPT charges between +0.760 and +0.889 e. $\mathrm{LiH}$, normally considered less ionic, has a $\mathrm{Li}$ charge of +0.654 e. The hydrogen halides have values following electronegativity expectations with $\mathrm{F}, \mathrm{Cl}, \mathrm{Br}$ and I charges of $-0.382,-0.184,-0.114$ and -0.040 e, respectively. $\mathrm{CO}$ has a negative GAPT charge on oxygen, expected from electronegativity considerations but contrary to the experimental sign of the almost null dipole moment that has oxygen at the positive pole. As pointed out by Bader and Matta ${ }^{73}$ polarization effects must be included in theoretical calculations to conciliate the small dipole moment with the large electronegativity difference between the carbon and oxygen atoms. These GAPT values correspond to a much larger charge difference for the $\mathrm{CO}$ dipole consistent with the above explanation. The NO GAPT charge separation of $\pm 0.151 \mathrm{e}$ is much smaller than the one in $\mathrm{CO}$ as the $\mathrm{NO}$ atoms have a smaller electronegativity difference than $\mathrm{CO}$.

GAPT charges have been calculated using quantum chemical methods at the MP2 level with a $6-311++G(3 d, 3 p)$ basis set for 30 molecules. Thirty four carbon atoms in these molecules resulted in a 0.059 e root mean square (rms) error. This is about $2 \%$ of the range of the carbon GAPT charges. Nineteen hydrogen atoms had a rms error of $0.013 \mathrm{e}$, nine fluorines, $0.044 \mathrm{e}$, nine chlorines, $0.045 \mathrm{e}$ and seven oxygens, $0.041 \mathrm{e}$.

In summary, the experimental GAPT charge values generally show behaviors expected of atomic charges. However, as will be shown later they correspond to physical parameters that should not be directly compared with most of the reported theoretical charge values.

\section{Experimental Infrared and GAPT Charges}

Assuming that an atomic point charge $\left(\mathrm{q}_{\alpha}\right)$ model adequately describes the molecular dipole moment, $\mathrm{p}=\Sigma \mathrm{q}_{\alpha} \sigma_{\alpha}=\mathrm{p}_{\text {charge }}$, for the $\sigma^{\text {th }}$ Cartesian direction and $\alpha^{\text {th }}$ atom, an atomic charge can be defined and determined using only experimental data for the special cases of linear and planar molecules. This is indeed enticing since no uncertainties in charge determinations would arise from basis set limitations, electron correlation approximations and different atomic partitioning schemes.

The modified charge charge-flux overlap (CCFO) mode $l^{74,75}$ was introduced appreciating the simplicity of the point charge model definition of the dipole moment and included polarization effects in the charges by adding the overlap contributions to Mulliken charges. In fact, for perpendicular and out-of-plane vibrations of linear and planar molecules, charge flux contributions cannot occur owing to symmetry and so these corrected Mulliken charges are the same as the out-of-plane elements of the APT. Now, the out-of-plane elements of the APTs, interpreted as charges, are consistent with the molecular equilibrium dipole moment value as a consequence of the rotational property of polar tensors. ${ }^{22}$ Since the polar tensors can be completely determined from only experimental information the Milani group has denominated the out-of-plane APT elements as experimental IR atomic charges. Infrared charges (IRC) have been determined from APTs using only experimental information and are reported in several papers. ${ }^{76,77}$ However, molecular planarity is not a necessary condition to apply the modified CCFO model as it has been 
applied to interpret the intensities of several nonplanar molecules. Approximate values of these charges have been recently determined from solely experimental data for nonplanar molecules. ${ }^{78-80}$

The infrared charges are conceptually different from the GAPT charges. They correspond to static equilibrium atomic charges that reproduce the permanent dipole moments of molecules and agree well with the results of calculational schemes to obtain charges by fitting molecular electrostatic potentials. ${ }^{81}$ On the other hand, GAPT charge values contain dynamic contributions. Adding terms to include atomic dipoles as well as point charges to describe the molecular dipole moment gives

$\mathrm{p}=\sum_{\alpha} \mathrm{q}_{\alpha} \sigma_{\alpha}+\sum_{\alpha} \mathrm{m}_{\alpha, \sigma}$

The molecular dipole moment derivative with respect to the $\vartheta^{\text {th }}$ Cartesian coordinate of atom $\alpha$ is given by

$\frac{\partial \mathrm{p}_{\sigma}}{\partial \vartheta_{\alpha}}=\mathrm{p}_{\sigma \vartheta}^{(\alpha)}=\mathrm{q}_{\alpha}+\sum_{\mathrm{i}} \sigma_{\mathrm{i}} \frac{\partial \mathrm{q}_{\mathrm{i}}}{\partial \vartheta_{\alpha}}+\sum_{\mathrm{i}} \frac{\partial \mathrm{m}_{\mathrm{i}, \sigma}}{\partial \vartheta_{\alpha}}$

containing the static atomic charge, $\mathrm{q}_{\alpha}$, a charge transfer term and a contribution from changes in atomic polarization where $m_{i, \sigma}$ represents the $\sigma^{\text {th }}$ Cartesian component of the dipole on the $\mathrm{i}^{\text {th }}$ atom. Since the GAPT charge is the trace of the atomic polar tensor matrix it also contains these three dynamic contributions. As such, the mean dipole moment derivative name used in spectroscopy seems to be a more adequate description of this parameter than "GAPT charge". But these dynamic contributions do not necessarily hinder its usefulness as it does satisfy the mathematical properties of an atomic charge. In fact, they may be quite useful in describing electronic structures as will be shown below.

The last column of Table 1 contains the values of the perpendicular polar tensor elements taken from the experimental polar tensor values of Table S1. These values are seen to be much different than the GAPT charges attesting to the importance of the dynamic contributions.

In the $\mathrm{X}_{2} \mathrm{CY}$ molecules in Table 1 the IR carbon charges vary between -0.15 and 0.53 e becoming more positive as more electronegative substituents bond to carbon. The corresponding range for the GAPT charges, 0.893 to $1.514 \mathrm{e}$, is much different but both charges follow the same trend with substituent electronegativity. The fluorine IR charge values in cis- and 1,1-difluoroethylene are very similar, -0.096 and -0.078 e, respectively, but much different than the respective similar GAPT charges, -0.372 and -0.423 e. The IR charge separation for the atoms of the $\mathrm{CH}$ bond in benzene is
0.119 e, whereas the CF separation is only 0.057 e in $\mathrm{C}_{6} \mathrm{~F}_{6}$, an unexpected result. However, the GAPT charge separation in $\mathrm{C}_{6} \mathrm{H}_{6}, 0.027 \mathrm{e}$, compared with the 0.428 e separation in $\mathrm{C}_{6} \mathrm{~F}_{6}$ is much more in line with chemical expectations. Both kinds of charges are in excellent agreement in acetylene with a positive hydrogen IR charge of $0.205 \mathrm{e}$ and a GAPT value of $0.201 \mathrm{e}$. The IR charges for CO successfully predict the polarity of the small $\mathrm{CO}$ moment with oxygen at the positive pole. This is to be expected for a static point charge model. The GAPT charges are not capable of this as explicit consideration of the atomic dipoles is very important in accounting for the unexpected $\mathrm{CO}$ polarity that is contrary to electronegativity expectations as already discussed above. ${ }^{73}$ Both types of charge have values in excellent agreement for the ionic diatomic molecules, $\mathrm{LiF}, \mathrm{LiCl}, \mathrm{NaF}, \mathrm{NaCl}$ and $\mathrm{KCl}$. Figure 4 shows a graph of the experimental IR and GAPT charges. In spite of the large differences in these values for a majority of molecules in Table 1, the numerical trends for individual groups of molecules results in an overall 0.77 correlation coefficient.

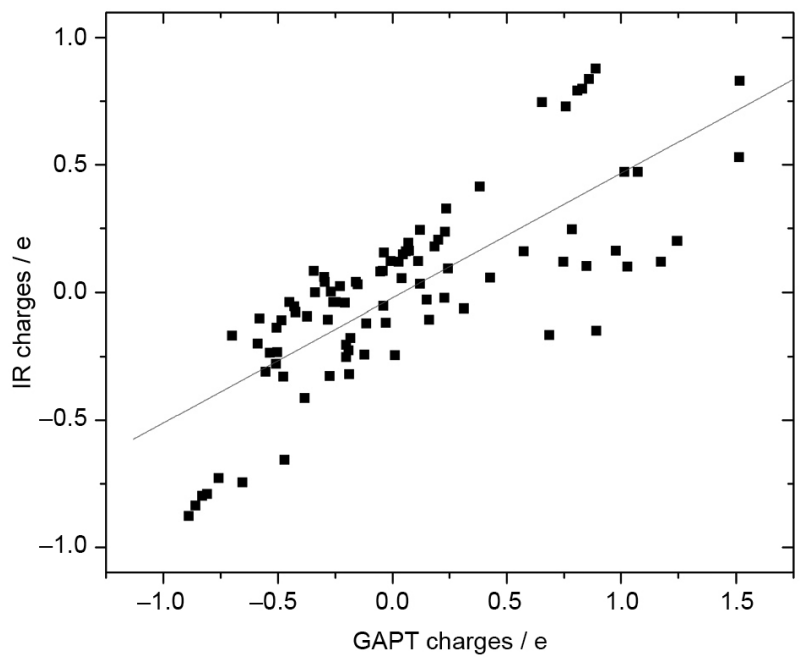

Figure 4. Experimental GAPT charges vs. experimental infrared charges.

\section{GAPT Charges and Core Ionization Ener- gies}

Core ionization energies of the B, C, N, O, F, Si, Ge, Sn, $\mathrm{P}, \mathrm{Cl}$ and $\mathrm{Br}$ atoms have been shown to have very interesting relationships with the experimental mean dipole moment derivatives. ${ }^{81-84}$

Siegbahn et al.'s simple potential model ${ }^{85}$ corrected for relaxation energy of the 1s core ionization energy of the carbon atom is given by

$\mathrm{E}_{\mathrm{C}, \text { ls }}=\mathrm{kq}_{\mathrm{C}}+\sum_{\mathrm{A} \neq \mathrm{C}} \mathrm{q}_{\mathrm{A}} / \mathrm{R}_{\mathrm{AC}}+\mathrm{E}_{\text {relax }}=\mathrm{kq}_{\mathrm{C}}+\mathrm{V}+\mathrm{E}_{\text {relax }}$ 
where $E_{C, 1 s}$ is the carbon $1 \mathrm{~s}$ core ionization energy, $\mathrm{q}_{\mathrm{A}}$ and $\mathrm{q}_{\mathrm{C}}$ are atomic charges, $\mathrm{R}_{\mathrm{AC}}$ is the internuclear distance between the $\mathrm{A}$ and $\mathrm{C}$ atoms and $\mathrm{E}_{\text {relax }}$ is the relaxation energy for the ionization process. The first two terms in this equation can be derived from purely electrostatic considerations ${ }^{85}$ or from quantum mechanical argument. ${ }^{86}$ The k parameter can be identified as the average electrostatic interaction between an electron located in a core orbital near the nucleus of an atom and a valence shell of unit charge around the nucleus, or in quantum chemical terms, the corresponding Coulomb integral. The first term on the right hand side of this equation represents the energy necessary to ionize an electron in a 1s orbital of the carbon atom. The second term is the electrostatic potential of this electron owing to the neighboring atoms in the molecule. The third term gives the relaxation energy of the carbon atom owing to its compensating changes in electron density on ionization.

According to equation 12, a graph of the core ionization energy, $\mathrm{E}_{\mathrm{C}, 1 \mathrm{~s}}$, corrected for the nearest neighbor electrostatic potential, $\mathrm{V}$, and the relaxation energy, $\mathrm{E}_{\text {relax }}$, against the atomic charge should result in a straight line. Here we demonstrate that the charge-like quality of the experimental mean dipole moment derivative, or GAPT charge, provides a much better fit to equation 12 than theoretically calculated Mulliken, charges from electrostatic potentials using a grid based method (CHELPG), and zero flux charges from QTAIM. The fluorochloromethane molecules are chosen for this as they vary from nonpolar to very polar molecules.

Figure 5 contains a graph of $\mathrm{E}_{\mathrm{C}, 1 \mathrm{~s}}-\mathrm{V}-\mathrm{E}_{\text {relax }}$ against the above charges calculated at the QCISD/cc-pVTZ level and the experimental GAPT charges. The corresponding data are given in Table 3 . The charge values used to prepare the data for the graph are presented in Table S2. As can be seen in the figure the experimental GAPT charges give a much better fit to Siegbahn's potential model than do the theoretical ones. It has an $\mathrm{R}^{2}$ value of 0.9974 , satisfactory for even accurate analytical calibration curves. It should be emphasized that the relaxation energy is the only theoretical quantity in equation 12 expressed with GAPT charges. The zero flux and Mulliken charges do provide reasonable fits to this equation, $\mathrm{R}^{2}$ equal to 0.9869 and 0.9712 , respectively, but they are significantly inferior to the experimental mean dipole moment derivative fit. The worst fit occurs for the

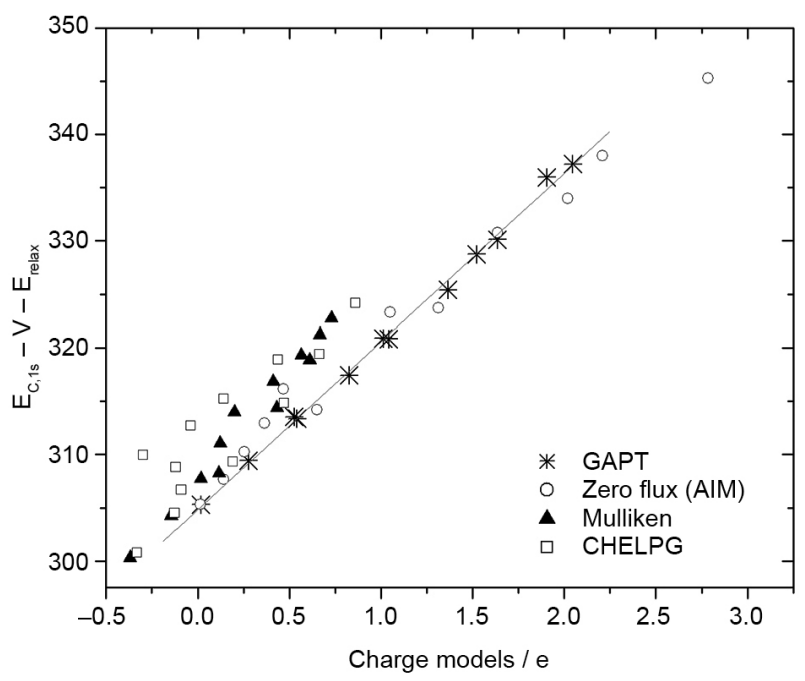

Figure 5. Experimental ionization energies of the 1s core electrons of the fluorochloromethanes corrected for relaxation energies and electrostatic potentials of terminal atoms as a function of the CHELPG, Mulliken, zero flux and GAPT charges.

Table 3. Experimental 1s core electron ionization energies, relaxation energies and electrostatic potentials owing to neighboring atoms for CHELPG, Mullikan, zero flux and mean dipole moment derivatives (eV)

\begin{tabular}{|c|c|c|c|c|c|c|}
\hline Molecule & $\mathrm{E}_{(\mathrm{ls,C})} / \mathrm{eV}$ & $\mathrm{E}_{(\mathrm{rel})} / \mathrm{eV}$ & $\mathrm{V}_{\text {(CHELPG) }} / \mathrm{eV}$ & $\mathrm{V}_{\text {(Mulliken) }} / \mathrm{eV}$ & $\mathrm{V}_{\text {(zero flux) }} / \mathrm{eV}$ & $\mathrm{V}_{(\mathrm{GAPT})} / \mathrm{eV}$ \\
\hline $\mathrm{CH}_{4}$ & 290.9 & -14.26 & 4.343 & 4.858 & -0.18 & -0.13 \\
\hline $\mathrm{CH}_{3} \mathrm{~F}$ & 293.6 & -13.97 & -1.735 & -0.671 & -6.66 & -5.78 \\
\hline $\mathrm{CH}_{2} \mathrm{~F}_{2}$ & 296.36 & -13.62 & -4.870 & -4.370 & -13.77 & -10.93 \\
\hline $\mathrm{CHF}_{3}$ & 299.1 & -13.25 & -7.078 & -6.496 & -21.66 & -16.41 \\
\hline $\mathrm{CF}_{4}$ & 301.85 & -12.92 & -9.424 & -7.991 & -30.48 & -22.45 \\
\hline $\mathrm{CH}_{3} \mathrm{Cl}$ & 292.48 & 14.75 & 2.686 & 3.002 & -0.4448 & -2.19 \\
\hline $\mathrm{CH}_{2} \mathrm{Cl}_{2}$ & 293.9 & -15.17 & 2.382 & 1.331 & -11.749 & -4.47 \\
\hline $\mathrm{CHCl}_{3}$ & 295.1 & -15.56 & 1.838 & -0.363 & -23.104 & -6.77 \\
\hline $\mathrm{CCl}_{4}$ & 296.39 & -15.95 & 2.395 & -1.620 & -37.862 & -8.49 \\
\hline $\mathrm{CCl}_{3} \mathrm{~F}$ & 297.54 & -15.44 & 0.240 & -3.855 & -10.359 & -12.42 \\
\hline $\mathrm{CCl}_{2} \mathrm{~F}_{2}$ & 298.93 & -14.78 & -1.523 & -5.608 & -17.047 & -16.43 \\
\hline $\mathrm{CClF}_{3}$ & 300.31 & -13.95 & -4.623 & -6.960 & -23.735 & -21.71 \\
\hline
\end{tabular}

$\mathrm{E}_{(\mathrm{ls}, \mathrm{C})}$ : experimental 1s core electron ionization energies; $\mathrm{E}_{(\text {(rel) }}$ : relaxation energies; $\mathrm{V}_{\text {(CHELPG) }}, \mathrm{V}_{\text {(Mulliken) }}, \mathrm{V}_{\text {(zero flux) }}$ and $\mathrm{V}_{\text {(GAPT) }}$ : electrostatic potentials owing to neighboring atoms for CHELPG, Mullikan, zero flux and mean dipole moment derivatives, respectively. 
CHELPG charges, $R^{2}=0.8019$, having considerable scatter of points around its expected regression line, much larger than that expected based on experimental uncertainty $( \pm 0.1 \mathrm{eV})$ in the ionization energies.

The results reported in this review indicate that the charge transfer and polarization effects given in equation 11 are important for explaining the linear dependence of core ionization energy on charge. As the ionization process is one of the most simple physicochemical transformations one can expect the charge transfer and polarization effects to be important in explaining chemical reactivities.

\section{Conclusions}

Clearly the dynamic parcels present in the GAPT charges somehow improve agreement with the core ionization energies. This fact alone is strong evidence of the necessity of including charge transfer and polarization effects for dynamic treatments. In most force fields, for example, CHELPG charges are fitted for large molecules in molecular simulations, through a static electrostatic model. We have shown here there is a risk of using charges without higher multipoles and possibly dynamic contributions to realistically describe electronic structural behavior. In some of these cases effects such as polarization and charge transfer have been artificially inserted through methods involving fluctuating charges, Drude oscillators and whole system charge conservation considerations ${ }^{87}$ Such effects should emerge naturally from the definition of atomic charge, and seemingly artificial practices may not be always reliable. For example, a molecular dynamics study of the conformation of trialanine ${ }^{88}$ evaluated with six different types of force fields surprisingly yielded qualitatively different results for the relative population found for each of the conformers.

The importance of polarization effects in reactivity and even molecular conformations have been recognized and addressed even by density functional developers as dispersion effects are now indispensable for the description of large systems in which van der Waals stabilization is crucial. For example, a theoretical study of the stacking interaction between substituted buckybowls and fullerenes showed that only dispersion-corrected functionals such as B97-D2 are able to predict its stabilization. ${ }^{89}$ Another study on the stability of a charged porphyrin derivative showed that dispersion is necessary to compensate its strong electrostatic repulsion and stability is only found through dispersion-corrected functionals like B3LYP-D3..$^{90}$

More work on experimental infrared intensities, polar tensors, GAPT charges and their applications are being carried out in our laboratory

\section{Supplementary Information}

Supplementary data (atomic polar tensor values determined from experimental infrared spectroscopic data (e) and charge and distance values used to calculate electrostatic potentials owing to neighboring atoms, $\mathrm{V}$ of Table 3) are available free of charge at http://jbcs.sbq.org.br as PDF file.

\section{Acknowledgments}

This review was made possible by the competent work of graduate students and postdoctoral researchers in our group between 1975 and 2009, namely Adalberto Bono Maurizio Sacchi Bassi, Benicio de Barros Neto, Mozart Neves Ramos, Elisabete Suto, Harley Paiva Martins Filho, João Bosco Lucena de Oliveira, Paulo Henrique Guadagnini, Anselmo Elcana de Oliveira, Roberto Luiz Andrade Haiduke and João Viçoso da Silva, Jr., all of whom helped determine polar tensors from experimental infrared intensities. Yoshiyuki Hase and Marcia Miguel Castro Ferreira of the IQ-Unicamp also collaborated in this effort. Financial support from the research granting agencies of Fundação de Amparo à Pesquisa do Estado de São Paulo (FAPESP), Conselho Nacional de Desenvolvimento Científico e Tecnológico (CNPq) and Coordenação de Aperfeiçoamento de Pessoal de Nível Superior (CAPES) throughout these years is very much appreciated.

Also W. E. R. thanks CNPq (grant 140711/2013-9) for graduate student fellowship. A. F. S. thanks FAPESP (grant 2014/21241-9) for postdoc research fellowship and R. E. B. thanks CNPq for a research fellowship. We are also grateful to FAPESP (for partial financial support of this work (grant 09/09678-4)).

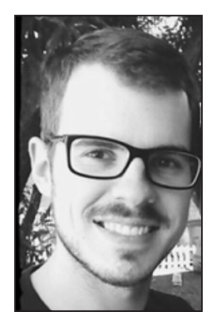

Wagner E. Richter received his BSc in Chemistry from State University of Maringá (2010) and his MSc (2013) and PhD (2016) degrees from University of Campinas, working with theoretical aspects of infrared spectroscopy. Currently he is an assistant professor in the Chemistry Department of the State University of Maringá.

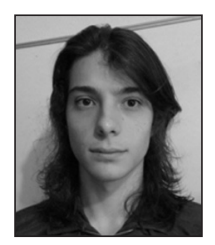

Leonardo J. Duarte is currently a chemistry undergraduate student at University of Campinas and has an undergraduate research scholarship. 


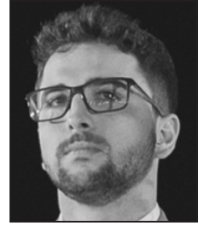

Arnaldo F. Silva received a triple major in teaching, technological and Bachelor in Chemistry from State University of Londrina (2008) and his MSc (2011) and $P h D$ (2014) degrees from University of Campinas. He specializes in infrared intensities and theoretical physical chemistry. Currently he is a research collaborator sponsored by FAPESP at the University of Campinas and The University of Manchester.

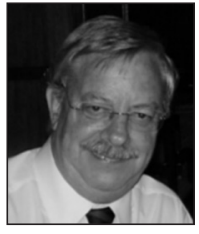

Roy E. Bruns received his BA degree from Southern Illinois University in 1963, his PhD from Oklahoma State University in 1968 and did post-doctoral research at the University of Florida with Willis Person. In 1971, he came to Brazil when Unicamp was in its infancy working in quantum chemistry and infrared spectroscopy, focusing on infrared band intensities. He brought the first computer program to Brazil for calculating molecular orbitals. In 1977, he became interested in chemometrics, starting the first course in Brasil on this subject and coauthoring the first book in Portuguese about statistical design of experiments that has sold over 17000 copies. Currently, he is an Emeritus Professor at the University of Campinas continuing work in the above areas appreciating music, beer-drinking and powerlifting.

\section{References}

1. Mulliken, R. S.; J. Chem. Phys. 1955, 23, 1833.

2. Löwdin, P. O.; J. Chem. Phys. 1950, 18, 365.

3. Löwdin, P. O.; Adv. Quantum Chem. 1970, 5, 185.

4. Reed, A. E.; Curtiss, L. A.; Weinhold, F.; Chem. Rev. 1988, 88, 899.

5. Reed, A. E.; Weinstock, R. B.; Weinhold, F.; J. Chem. Phys. 1985, 83, 735 .

6. Besler, B. H.; Merz Jr., K. M.; Kollman, P. A.; J. Comput. Chem. 1990, 11, 431

7. Singh, U. C.; Kollman, P. A.; J. Comput. Chem. 1984, 5, 129.

8. Chirlian, L. E.; Francl, M. M.; J. Comput. Chem. 1990, 8, 894

9. Breneman, C. M.; Wiberg, K. B.; J. Comput. Chem. 1990, 11, 361.

10. Hirshfeld, F. L.; Theor. Chem. Acc. 1977, 44, 129.

11. Guerra, C. F.; Handgraaf, J. W.; Baerends, E. J.; Bickelhaupt, F. M.; J. Comput. Chem. 2004, 25, 189.

12. Koritsanszky, T. S.; Coopens, P.; Chem. Rev. 2001, 101, 1583.

13. Bader, R. F. W.; Atoms in Molecules, A Quantum Theory; Clarendon Press: Oxford, 1990.

14. Platts, J. A.; Overgaard, J.; Jones, C.; Iversen, B. B.; Stasch, A.; J. Phys. Chem. A 2011, 115, 194.
15. Volkov, A.; Gatti, C.; Abramov, Y.; Coppens, P.; Acta Crystallogr., Sect. A: Found. Crystallogr. 2000, 56, 252.

16. Jaradat, D. M. M.; Mebs, S.; Checinska, L.; Luger, P.; Carbohydr. Res. 2007, 342, 1480.

17. Farrugia, L. J.; Evans, C.; Tegel, M.; J. Phys. Chem. A 2006, 110, 7952.

18. Newton, J. H.; Person, W. B.; J. Chem. Phys. 1976, 64, 3036.

19. Cioslovski, J.; J. Am. Chem. Soc. 1989, 111, 8333.

20. Gussoni, M.; Ramos, M. N.; Castiglioni, C.; Zerbi, G.; Chem. Phys. Lett. 1987, 142, 515.

21. Ramos, M. N.; Gussoni, M.; Castiglioni, C.; Zerbi, G.; Chem. Phys. Lett. 1988, 151, 397.

22. Dinur, U.; Hagler, A. T.; J. Chem. Phys. 1989, 91, 2949.

23. Biarge, J. F.; Herranz, J.; Morcillo, J.; An. R. Soc. Esp. Fis. Quim. 1961, 57, 81.

24. Overend, J. In Infrared Spectroscopy and Molecular Structure; Davies, M., ed.; Elsevier: New York, 1963, ch. 10.

25. Person, W. B.; Newton, J. H.; J. Chem. Phys. 1974, 61, 1040.

26. Barros Neto, B.; Ferreira, M. M. C.; Scarminio, I. S.; Bruns, R. E.; J. Phys. Chem. 1989, 93, 1728.

27. Bassi, A. B. M. S.; Bruns, R. E.; J. Chem. Phys. 1975, 62, 3235.

28. Bassi, A. B. M. S.; Bruns, R. E.; J. Phys. Chem. 1975, 79, 1880.

29. Kagel, R. O.; Powell, D. L.; Overend, J.; Ramos, M. N.; Bassi, A. B. M. S.; Bruns, R. E.; J. Chem. Phys. 1983, 78, 7029.

30. Suto, E.; Ramos, M. N.; Bruns, R. E.; J. Phys. Chem. 1993, 97 , 6161.

31. Hopper, M. J.; Overend, J.; Ramos, M. N.; Bassi, A. B. M. S.; Bruns, R. E.; J. Chem. Phys. 1983, 79, 19.

32. Silva, J. B. P.; Ramos, M. N.; Suto, E.; Bruns, R. E.; J. Phys. Chem. A 1997, 101, 6293.

33. Kagel, R. O.; Powell, D. L.; Overend, J.; Ramos, M. N.; Bassi, A. B. M. S.; Bruns, R. E.; J. Chem. Phys. 1982, 77, 1099.

34. Newton, J. H.; Person, W. B.; J. Phys. Chem. 1978, 82, 226.

35. Bode, J. H. G.; Smit, W. M. A.; Visser, T.; Verkruijsse, H. D.; J. Chem. Phys. 1980, 72, 6560.

36. Average values of the (+----) and (+-+--) sets of Person, W. B.; Newton, J. H.; J. Chem. Phys. 1974, 61, 1040.

37. Koga, Y.; Kondo, S.; Nakanaga, T.; Saeki, S.; J. Chem. Phys. 1979, 71, 2404.

38. Haiduke, R. L. A.; Hase, Y.; Bruns, R. E.; Spectrochim. Acta, Part A 2001, 57, 1369.

39. Levin, I. W.; Pearce, R. A. R.; J. Chem. Phys. 1978, 69, 2196.

40. Silva, J. V.; Oliveira, A. E.; Hase, Y.; Bruns, R. E.; J. Phys. Chem. A 2009, 113, 7972 .

41. Barros Neto, B.; Bruns, R. E.; J. Chem. Phys. 1978, 68, 5451. 42. Jona, P.; Gussoni, M.; Zerbi, G.; J. Phys. Chem. 1981, 85, 2210.

43. Kim, K.; King, W. T.; J. Mol. Struct. 1979, 57, 201.

44. Smit, W. M. A.; Van Straten, A. J.; Visser, T.; J. Mol. Struct. 1978, 48, 177.

45. Kim, K.; King, W. T.; J. Chem. Phys. 1979, 71, 1967. 
46. Person, W. B.; Brown, K. G.; Steele, D.; Peters, D.; J. Phys. Chem. 1981, 85, 1998.

47. Ferreira, M. M. C.; Bassi, A. B. M. S.; J. Chem. Phys. 1984, $81,6$.

48. Oliveira, A. E.; Guadagnini, P. H.; Custodio, R.; Bruns, R. E.; J. Phys. Chem. A 1998, 102, 4615.

49. Koga, Y.; Kondo, S.; Saeki, S.; Person, W. B.; J. Phys. Chem. 1984, 88, 3152.

50. Zilles, B. A.; Person, W. B.; J. Chem. Phys. 1983, 79, 65.

51. Bassi, A. B. M. S.; Bruns, R. E.; J. Phys. Chem. 1976, 80, 2768.

52. Bassi, A. B. M. S.; Bruns, R. E.; J. Chem. Phys. 1978, 68, 5448.

53. Bassi, A. B. M. S.; Bruns, R. E.; J. Chem. Phys. 1976, 64, 3053.

54. Kim, K.; King, W. T.; J. Chem. Phys. 1984, 80, 974.

55. Kim, K.; King, W. T.; J. Chem. Phys. 1984, 80, 969.

56. Polavarapu, P. L.; Hess Jr., B. A.; Schaad, L. J.; J. Mol. Spectrosc. 1985, 109, 22.

57. Haiduke, R. L. A.; Bruns, R. E.; J. Phys. Chem. A 2005, 109, 2680.

58. Bruns, R. E.; Brown, R. E.; J. Chem. Phys. 1978, 68, 880.

59. Suto, E.; Martins, H. P.; Bruns, R. E.; J. Mol. Struct.: THEOCHEM 1993, 282, 81.

60. Suto, E.; Bruns, R. E.; Neto, B. B.; J. Phys. Chem 1991, 95 , 9716.

61. Kim, K.; King, W. T.; J. Chem. Phys. 1980, 73, 5591.

62. Oliveira, A. E.; Haiduke, R. L. A.; Bruns, R. E.; Spectrochim. Acta, Part A 2000, 56, 1329.

63. Martins, H. P.; Bruns, R. E.; Suto, E.; J. Phys. Chem. 1993, 97 , 4354.

64. Martins Filho, H. P.; Oliveira, J. B. L.; Bruns, R. E.; J. Mol. Struct. 1995, 335, 113.

65. Kim, K.; King, W. T.; J. Chem. Phys. 1984, 80, 978.

66. Suto, E.; Ferreira, M. M. C.; Bruns, R. E.; J. Comput. Chem. 1991, 12,885 .

67. Oliveira, A. E.; Bruns, R. E.; Spectrochim. Acta, Part A 1999, 55,2215 .

68. Martins, H. P.; Oliveira, J. B. L.; Guadagnini, P. H.; Bruns, R. E.; J. Phys. Chem. 1995, 99, 11357.

69. Barros Neto, B.; Bruns, R. E.; J. Phys. Chem. 1990, 94, 1764.

70. Scarminio, I. S.; Barros Neto, B.; Oliveira, A. E.; Bruns, R. E.; J. Mol. Struct.: THEOCHEM 2001, 539, 149.

71. Silva, A. F.; Richter, W. E.; Bassi, A. B. M. S.; Bruns, R. E.; Phys. Chem. Chem. Phys. 2015, 17, 30378.
72. Haiduke, R. L. A.; Oliveira, A. E.; Moreira, N. H.; Bruns, R. E.; J. Phys. Chem. A 2004, 108, 866.

73. Bader, R. F. W.; Matta, C. F.; J. Phys. Chem. A 2004, 108, 8385.

74. Gussoni, M.; Ramos, M. N.; Castiglione, C.; Zerbi, G.; J. Mol. Struct. 1988, 174, 47.

75. Rusu, V. H.; Ramos, M. N.; Longo, R. L.; J. Mol. Struct. 2011, 993, 86.

76. Milani, A.; Castiglioni, C.; J. Mol. Struct.: THEOCHEM 2010, 955, 158.

77. Milani, A.; Castiglioni, C.; J. Phys. Chem. A 2010, 114, 624.

78. Milani, A.; Tommasini, M.; Castiglioni, C.; Theor. Chem. Acc. 2012, 131, 1139.

79. Galimberti, D.; Milani, A.; Castiglioni, C.; J. Chem. Phys. 2013, 138, 074304.

80. Galimberti, D.; Milani, A.; Castiglioni, C.; J. Chem. Phys. 2013, 139, 164115.

81. Guadagnini, P. H.; Oliveira, A. E.; Bruns, R. E.; Barros Neto, B.; J. Am. Chem. Soc. 1997, 119, 4224.

82. Haiduke, R. L. A.; Oliveira, A. E.; Bruns, R. E.; J. Phys. Chem. A 2002, 106, 1824.

83. Oliveira, A. E.; Guadagnini, P. H.; Custodio, R.; Bruns, R. E.; J. Phys. Chem. A 1998, 102, 4615.

84. Oliveira, A. E.; Guadagnini, P. H.; Haiduke, R. L. A.; Bruns, R. E.; J. Phys. Chem. A 1999, 103, 4918.

85. Siegbahn, K.; Nordling, C.; Johansson, G.; Heden, P. F.; Hamrin, K.; Gelius, U.; Bergmark, T.; Werne, L. O.; Manne, R.; Baer, Y.; ESCA Applied to Free Molecules; North-Holland: Amsterdam, 1969.

86. Gelius, U.; Phys. Scr. 1974, 9, 133.

87. Rick, S. W.; Stuart, S. J.; Rev. Comput. Chem. 2002, 18, 89.

88. Mu, Y.; Kosov, D. S.; Stock, G.; J. Phys. Chem. B 2003, 107, 5064.

89. Josa, D.; Rodríguez-Otero, J.; Cabaleiro-Lago, E. M.; Santos, L. A.; Ramalho, T. C.; J. Phys. Chem. A 2014, 118, 9521.

90. Ehrlich, S.; Moellmann, J.; Grimme, S.; Acc. Chem. Res. 2013, $46,916$.

Submitted: February 18, 2016

Published online: April 6, 2016

FAPESP has sponsored the publication of this article. 